\title{
Genetic structure of Aedes aegypti in the city of Córdoba (Argentina), a recently reinfested area
}

\author{
Norma B Julio, Marina B Chiappero/ ${ }^{+}$, Hernán J Rossi, Juan C Rondan Dueñas, Cristina N Gardenal \\ Cátedra de Genética de Poblaciones y Evolución, Facultad de Ciencias Exactas, Físicas y Naturales, Universidad Nacional de Córdoba, \\ Av. Vélez Sarsfield 299, 5000 Córdoba, Argentina
}

To understand the transmission of a vector-borne disease, knowledge of the magnitude of dispersal among vector populations is essential because of its influence on pathogen transfer. The principal vector of dengue, the most common arboviral disease in the world, is the mosquito Aedes aegypti (L.). This tropical and subtropical species is native to Africa but has dispersed worldwide since the XV century. In Argentina, the species was declared eradicated in 1963, but has reinfested the country in recent years. In the present work, we used RAPD-PCR markers to assess the levels of genetic variability and differentiation among populations of Ae. aegypti (the vector of dengue and yellow fever) in Córdoba, the second largest city in Argentina. We detected similar levels of genetic variability $\left(H_{e}\right.$ between 0.351-0.404) across samples and significant genetic differentiation between most population pairs within the city ( $F_{S T}$ between 0.0013-0.0253). Genetic distances indicate that there are three distinct groups, formed predominantly by populations that are connected by, or near, main roads. This suggests that, in addition to other factors such as availability of oviposition sites or step-by-step migration, passive transport plays an important role in gene flow within the city.

Key words: Aedes aegypti - genetic structure - gene flow - RAPD-PCR markers

The mosquito Aedes aegypti (L.), a tropical and subtropical species native to Africa, is the principal vector of dengue, the most common arboviral disease in the world. The mosquito has dispersed worldwide since the XV century, probably favoured by ever-increasing transcontinental trading activities. The species is currently found in all continents between latitudes $35^{\circ} \mathrm{N}-35^{\circ} \mathrm{S}$ and about two thirds of the world's population lives in areas infested with Ae. aegypti (Pinheiro \& Corber 1997, Gibbons \& Vaughn 2002). Ae. aegypti is a domestic species; females oviposit mostly in artificial containers in and around human dwellings and feed preferentially on humans (Gubler 1998).

Knowledge of dispersal among vector populations is essential for understanding the transmission of the disease among human populations because of its influence on pathogen transfer and the spread of genetically determined traits of epidemiological importance, such as insecticide resistance and vectorial competence. Dispersal is also one of the main forces that shape the spatial distribution of neutral genetic variation. Several factors influence the levels and patterns of dispersal of Ae. aegypti: climate conditions, type and availability of oviposition sites, contiguous areas of suitable habitat, human control

Financial support: Agencia Nacional de Promoción Científica y Tecnológica of Argentina (PICT 14530), Secretaría de Ciencia y Técnica, Universidad Nacional de Córdoba

+ Corresponding author: mchiappero@efn.unc.edu.ar

Received 28 January 2009

Accepted 19 June 2009 efforts, colonization history and passive transport by humans. The magnitude of active dispersal capacity of $A e$. aegypti remains controversial because recorded dispersal distances have been variable. Honorio et al. (2003) observed dispersal at distances between 100-800 $\mathrm{m}$ in an urban area of the state of Rio de Janeiro (RJ), Brazil. However, Harrington et al. (2005), in experiments conducted in Puerto Rico and Thailand, found that most individuals disperse a few tens of meters and very few individuals disperse up to $500 \mathrm{~m}$.

In Argentina, Ae. aegypti was declared eradicated in 1963 as a result of a campaign organized by the Pan American Health Organization, which succeeded in eliminating the species from most countries in the Americas. In subsequent decades, however, the species reinfested all of its former distribution areas, being detected again in the Northeastern end of Argentina in 1986 (Bejarano 1968, Pinheiro \& Corber 1997, Gibbons \& Vaughn 2002). During a surveillance program implemented by the Ministry of Health of Córdoba Province (Central Argentina), the presence of mosquitoes was detected in five localities between 1994-1996, including Córdoba, the capital city (Avilés et al. 1997).

The genetic structure of Ae. aegypti populations within cities have been extensively studied in Southeast Asian cities of Cambodia, Vietnam and Thailand (Tran Khanh et al. 1999, Huber et al. 2002, 2004, Paupy et al. 2004a, b, Bosio et al. 2005). In general, samples from different neighbourhoods showed significant genetic differentiation. The number, type and proximity of suitable breeding sites and human population density significantly influenced the dispersal of mosquitoes. The few studies of genetic structure conducted in South American cities showed similar trends (Ocampo \& Wesson 2004, da Costa-Ribeiro et al. 2006). Córdoba (64' $12^{\prime} \mathrm{W} 31^{\circ} 22^{\prime} \mathrm{S}$; 
$1,250,000$ inhabitants), the second largest city in Argentina, is an important commercial and industrial centre, as it is located at the crossroads of many national and international routes. In the present work, levels of genetic variation and microgeographic differentiation among seven neighbourhoods in Córdoba were assessed using RAPD-PCR markers, with the aim of examining local patterns of genetic structure of Ae. aegypti populations.

\section{MATERIALS AND METHODS}

Sampling - In February 2002, 3rd and 4th instar larvae were collected from artificial containers located in seven neighbourhoods of Córdoba that were between 4-16 km apart (Fig. 1): Yofre $(\mathrm{n}=16)$, Parque Liceo $(\mathrm{n}=$ 20), Las Flores $(n=23)$, San Lorenzo $(n=18)$, Cerro de las Rosas $(\mathrm{n}=16)$, Observatorio $(\mathrm{n}=25)$ and Los Robles $(\mathrm{n}=20)$. In all cases, except the sample from Cerro de las Rosas, the artificial containers consisted of old tires accumulated outdoors in used tire shops. The sample from Cerro de las Rosas was obtained from a container placed ad hoc outside a house. The larvae were reared to maturity under laboratory conditions. Adults were frozen and stored at $-30^{\circ} \mathrm{C}$ until processing.

$R A P D-P C R$ procedures - DNA was extracted from mosquitoes as described by Levitan and Grosberg (1993). PCR were carried out as described by de Sousa et al. (2001). In each reaction, a negative control (including $\mathrm{ddH}_{2} \mathrm{O}$ instead of mosquito DNA) was included to test for contamination with foreign DNA. To test for band repeatability, a positive control consisting of DNA of one individual (CR5) was included in each PCR reaction and electrophoresed. Additionally, DNA from approximately $25 \%$ of the individuals of each population was amplified

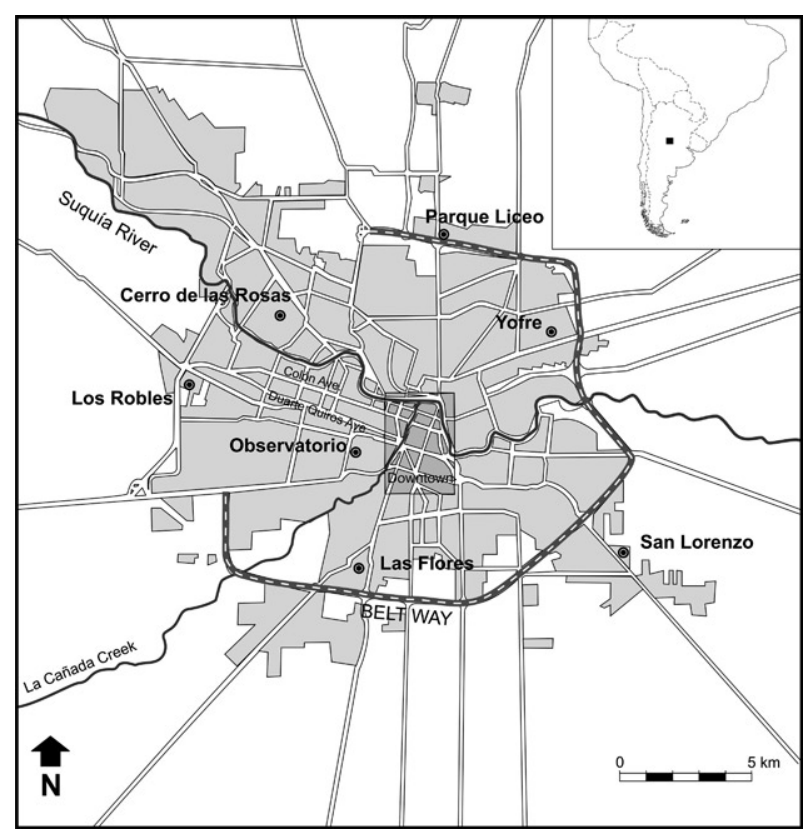

Fig. 1: map of Córdoba city showing the geographic location of the seven populations of Aedes aegypti analysed. twice on different days. In both cases, we checked that the same bands were amplified.

The same arbitrary primers analyzed by de Sousa et al. (2001) were used for PCR amplifications: OP-A02 (5, -TGCCGAGCTG-3'), OP-B03 (5'-ACTTCGACAA-3') and OP-B13 (5'-TTCCCCCGCT-3') from Operon Technologies (Alameda, CA). The same 17 bands used by de Sousa et al. (2001) to analyze the genetic differentiation among Ae. aegypti from five cities in Argentina were screened. Additionally, another 20 arbitrary primers (kits A and B from Biodynamics SRL, Buenos Aires, Argentina) were screened to obtain more loci for the microgeographic study proposed in this work. For our analyses, we selected three RAPD primers that produced polymorphic bands that were repeatable, bright and well separated on gels: BD-A02 (5'-GGTGCGGGA A-3'), BD-A06 (5'-GAGTCTCAGG-3') and BD-A10 (5' -ACGGCGTATG- 3').

PCR products were separated by electrophoresis on $1.8 \%$ agarose gels stained with ethidium bromide in Tris-borate-EDTA buffer (Sambrook et al. 1989). Gels were run for $6 \mathrm{~h}$ at $1.5 \mathrm{~V} / \mathrm{cm}$ and photographed on a UV transilluminator.

Statistical analyses - Only bright and repeatable RAPD bands were used for analyses. Bands were scored as present (1) or absent (0). These data were used to estimate allele frequencies, assuming that each RAPD band of a given molecular size was the product of a dominant allele at a given locus and that genotype frequencies at RAPD loci were in HardyWeinberg equilibrium, as demonstrated by de Sousa et al. (2000). These calculations were performed with AFLPsurv (Vekemans et al. 2002) using the Bayesian method with non-uniform prior distribution of allele frequencies. Zhivotovsky (1999) demonstrated that this method gives the most accurate estimation of allele frequencies for dominant markers. These allele frequencies were used for all subsequent calculations.

Levels of genetic variability for each neighbourhood were estimated according to Lynch and Milligan (1994) as the percentage of polymorphic loci ( $95 \%$ criterion) and the unbiased expected heterozygosity (H) (Nei 1978). Ninety-five percent confidence intervals were calculated for $\mathrm{H}_{\mathrm{e}}$ values. These calculations were performed using the program AFLPsurv (Vekemans et al. 2002).

Genetic differentiation among neighbourhoods was estimated by means of Wright's (1978) $\mathrm{F}_{\mathrm{ST}}$ index. Calculations were performed with AFLPsurv. To test the hypothesis of isolation by distance, the correlation between genetic differentiation between pairs of populations and geographic distance was assessed according to Rousset (1997): pairwise $F_{S T}$ values were calculated with AFLPsurv, transformed as $\mathrm{F}_{\mathrm{ST}} /\left(1-\mathrm{F}_{\mathrm{ST}}\right)$ and their correlation with the ln of geographic distances between populations was calculated with a Mantel test using the IBD Web service (Jensen et al. 2005).

Reynolds et al. (1983) genetic distances among neighbourhoods were calculated using AFLPsurv and represented graphically in a multi-dimensional scaling graphic (MDS). 


\section{RESULTS}

A total of 50 RAPD bands, ranging in size from 448$1,769 \mathrm{bp}$, were selected for analyses, 17 of which were the same fragments used by de Sousa et al. (2001) to analyse samples from different cities in Argentina. Examples of the amplification patterns obtained with the new RAPD primers are shown in Fig. 2.
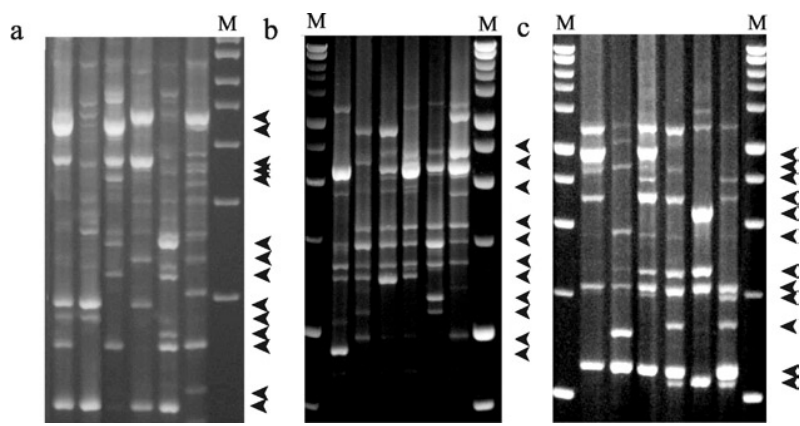

Fig. 2: example of the band patterns obtained for RAPD primers BDA02 (a) BD-A06 (b) and BD-A10 (c). Arrows indicate the bands selected for analyses.

Table I shows the expected $\mathrm{H}$ values and proportion of polymorphic loci. There were no differences in levels of $\mathrm{H}$ among mosquito populations in the different neighbourhoods. Overall genetic differentiation among all populations was low but statistically significant $\left(\mathrm{F}_{\mathrm{ST}}\right.$ $=0.0103 ; \mathrm{p}<0.05) ; \mathrm{F}_{\mathrm{ST}}$ decreased one order of magnitude, but still remained significant when the furthermost population was removed from the analysis $\left(\mathrm{F}_{\mathrm{ST}}=0.007\right.$; $\mathrm{p}<0.05) . \mathrm{F}_{\mathrm{ST}}$ values between pairs of populations ranged from $0.0013-0.0253$ (Table II); $\mathrm{F}_{\mathrm{ST}} /\left(1-\mathrm{F}_{\mathrm{ST}}\right)$ showed a non-

\section{TABLE I}

Levels of genetic variability in population samples of Aedes aegypti from different neighbourhoods in Córdoba city estimated as percentage of polymorphic loci ( $95 \%$ criterion; P95\%) and expected mean heterozygosity $\left(\mathrm{H}_{\mathrm{e}}\right)$

\begin{tabular}{lccc}
\hline Population & $\begin{array}{c}\text { Specimens } \\
\mathrm{n}\end{array}$ & $\mathrm{P}_{95 \%}$ & $\begin{array}{c}\mathrm{H}_{\mathrm{e}} \\
(95 \% \mathrm{CI})^{a}\end{array}$ \\
\hline Yofre & 16 & 100 & $0.404(0.377-0.431)$ \\
Parque Liceo & 18 & 100 & $0.394(0.366-0.423)$ \\
Las Flores & 22 & 100 & $0.372(0.343-0.401)$ \\
San Lorenzo & 17 & 92 & $0.351(0.310-0.393)$ \\
Cerro de las Rosas & 15 & 100 & $0.386(0.355-0.417)$ \\
Observatorio & 24 & 100 & $0.391(0.358-0.424)$ \\
Los Robles & 19 & 98 & $0.393(0.363-0.432)$ \\
\hline
\end{tabular}

$a$ : values were calculated on the basis of Bayesian estimation of allele frequencies considering a non-uniform prior distribution. significant correlation with geographic distance (Mantel test: $r=0.320, p=0.113$ ) (Fig. 3A). When the furthermost population (San Lorenzo) was removed from analysis, the correlation disappeared (Mantel test $\mathrm{r}=-0.041, \mathrm{p}=$ 0.540). San Lorenzo was the most differentiated population and showed highly significant $\mathrm{F}_{\mathrm{ST}}$ values in comparison with all other samples. This was also seen in the MDS graphic of Reynolds et al. (1983) distances (Fig. 4 ), where a large genetic distance was observed between San Lorenzo and the other neighbourhoods. The remaining populations clustered into two groups: Observatorio with Los Robles in one group and Yofre, Parque Liceo, Las Flores and Cerro de las Rosas in another group.

\section{TABLE II}

$\mathrm{F}_{\mathrm{ST}}$ values between pairs of populations of Aedes aegypti in Córdoba city

\begin{tabular}{lllllll}
\hline Y & PL & LF & SL & CR & O \\
\hline
\end{tabular}

Yofre

(Y)

Parque Liceo 0.0014

(PL)

Las Flores $\quad 0.00320 .0073^{a}$

(LF)

San Lorenzo $\quad 0.0222^{c} \quad 0.0165^{b} \quad 0.0217^{c}$

(SL)

$\begin{array}{lllll}\text { Cerro de } & 0.0013 & 0.0032 & 0.0024 & 0.0112^{a}\end{array}$

las Rosas

(CR)

Observatorio $\begin{array}{lllll}0.0165^{c} & 0.0099^{b} & 0.0133^{b} & 0.0184^{c} & 0.0051^{a}\end{array}$

(O)

Los Robles $\begin{array}{llllll}0.0046^{a} & 0.0122^{b} & 0.0144^{c} & 0.0253^{c} & 0.0046 & 0.0032\end{array}$ (LR)

$a: \mathrm{p}<0.05 ; b: \mathrm{p}<0.01 ; c: \mathrm{p}<0.001$.

\section{DISCUSSION}

In this paper, we analysed the levels of genetic variation and microgeographic differentiation among seven neighbourhoods in Córdoba, using RAPD-PCR as genetic markers.

Populations of Ae. aegypti from Córdoba showed high levels of genetic variability, as revealed by the analysis of 50 RAPD loci. Values of expected $\mathrm{H}$ were similar to those found previously by de Sousa et al. (2001) in several Argentine cities using only 17 RAPD loci. Likewise, levels of variability were similar to those found in other populations from Brazil (Ayres et al. 2003, Paduan et al. 2006), Puerto Rico (Apostol et al. 1996) and Mexico (Gorrochotegui-Escalante et al. 2000), using the same molecular markers. Rondán Dueñas (2005) reported that haplotype diversity values at the mitochondrial control region in Ae. aegypti from Córdoba were among the highest in Argentina. He also found that the haplo- 


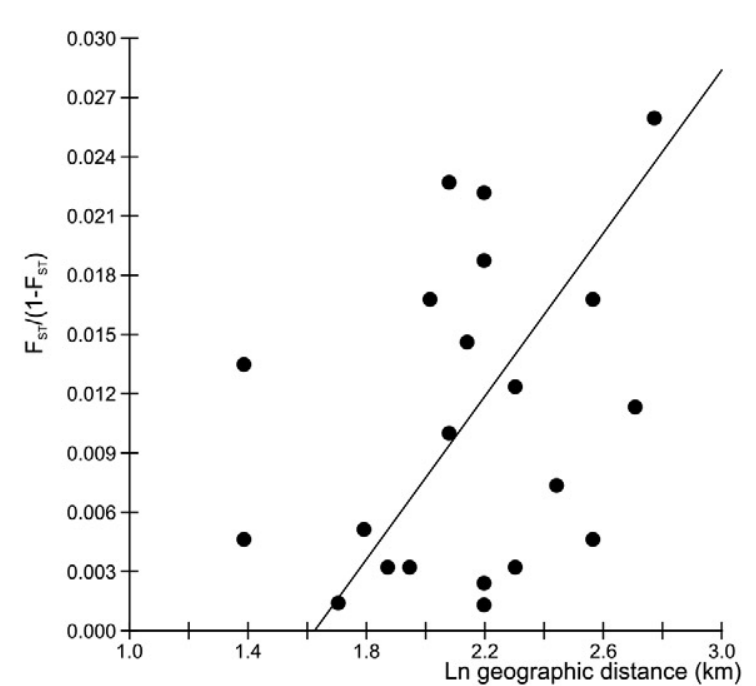

Fig. 3: scatterplot of genetic differentiation between pairs of populations of Aedes aegypti from Córdoba city against the ln of geographic distances separating them.

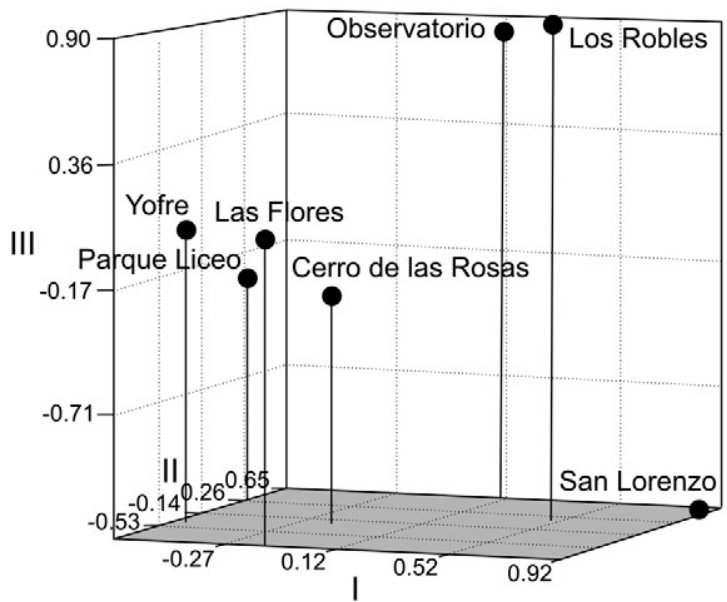

Fig. 4: multidimensional scaling plot of Reynolds et al. (1983) genetic distances among populations of Aedes aegypti from the city of Córdoba.

types detected in Argentine cities formed three phylogenetically distinct clusters. One cluster was restricted to populations from the northern part of the country and Bolivia, a second cluster included populations native to Northwestern Argentina (probably relicts of the eradication campaigns) and a third cluster included populations recently introduced by passive transportation from Brazil. The latter two haplogroups converged in Córdoba, explaining, at least in part, the high diversity found in this recently colonized area.

The level of genetic differentiation among Ae. aegypti populations from different neighbourhoods in densely populated cities seems to be related to factors such as population density (favouring feeding of female mosquitoes) and the increased availability of breeding sites in places without a piped water supply (because water is stored in open containers). For example, Huber et al. (2004) found that in Ho Chi Minh City (Vietnam), the level of genetic differentiation among populations from the outskirts of the city, where human density is lower and water is stored in open containers, is twice as high as among populations in downtown areas, where human density is high and there is a piped water supply. Similar results were obtained in other Southeast Asian cities, such as Chiang Mai in Thailand (Mousson et al. 2002) and Phnom Penh in Cambodia (Paupy et al. 2004a, b). Climatic factors, such as seasonality of temperature and rainfall, also influence the level of genetic differentiation among mosquito populations. Paupy et al. (2004a) found more genetic differentiation among Ae. aegypti collected from temporary water containers than among those from permanent domestic water storage in a single, 400 metre-long street in Phnom Penh. In RJ, Brazil, differentiation among populations was lower during the dry season, when females needed to disperse farther to find suitable breeding sites. The periodicity of application of insecticide treatments was found to be another factor that determines the genetic structure of Ae. aegypti because treatments cause periodic population bottlenecks that enhance genetic differentiation, as reported for populations from Cali (Colombia) (Ocampo $\&$ Wesson 2004) and several Asian cities (Mousson et al. 2002, Paupy et al. 2005).

In the present work, we found an overall small but statistically significant genetic differentiation among mosquitoes from different neighbourhoods in Córdoba, which showed no correlation with geographic distance. Two conditions are necessary for a pattern of isolation by distance to occur: higher probability of short-distance than long-distance gene flow and enough time for the pattern to be established. Otherwise, a random distribution of allele frequencies will be found, with high differentiation among populations when gene flow is restricted, or with non-significant $\mathrm{F}_{\mathrm{ST}}$ values when gene flow is common (Hutchison \& Templeton 1999). Given that the reinfestation of Córdoba is a relatively recent event (10-15 years), the significant pairwise $\mathrm{F}_{\mathrm{ST}}$ values would indicate that gene flow between the sampled populations is low. Sampling points were located more than $4 \mathrm{~km}$ apart, a distance much larger than the flight range of the species, but within residential neighbourhoods that had low human densities and consisted mostly of houses with gardens and backyards. In Buenos Aires (the capital city of Argentina), Carbajo et al. (2006) found that oviposition activity was higher in areas with a larger proportion of houses and lower human density, compared to more urbanized areas with high-rise buildings and higher human density. A positive association was also found between oviposition and industrial sites, possibly due to a high density of water containers. Vezzani et al. (2005) also found that, in Buenos Aires, the microhabitats most favourable for reproduction of Ae. aegypti were sites less exposed to sunlight, such as shaded and vegetated neighbourhoods, these environments are also frequent in the neighbourhoods sampled in Córdoba. Although a step-by-step migration of mosquitoes between 
neighbourhoods is highly possible, had dispersion been active, it would have been reflected in lower or nonsignificant $\mathrm{F}_{\mathrm{ST}}$ values. An explanation for our result is that short-distance gene flow would not be enough to balance genetic drift. In Córdoba, there have been neither extensive insecticide applications nor extensive mosquito eradication campaigns, such as those to which strong drift events have been attributed in other cities. However, unlike the climate of Southeast Asian cities and the Latin-American cities studied so far, Córdoba's climate is temperate semi-arid, with winter temperatures that can fall below $0^{\circ} \mathrm{C}$ and rainfall concentrated almost completely in the summer months. Domínguez et al. (2000) found that adults and larvae of Ae. aegypti do not survive through the winter in Córdoba. Oviposition significantly decreases during autumn, stopping when temperature falls to less than $17^{\circ} \mathrm{C}$ and the first spring cohort originates from overwintering eggs. Therefore, the climatic pattern would cause yearly genetic drift events that increase interpopulation differentiation.

On the other hand, genetic distances between population pairs show three clear groups (Fig. 4). In two of the groups, populations are connected by main roads: Observatorio and Los Robles by Colón and Duarte Quirós Avenues and Parque Liceo, Yofre and Las Flores by the beltway that surrounds most of the city (Fig. 1). At the spatial scale of the present study, passive transport would be the most influential means of dispersal. The third group includes only the sample from San Lorenzo, which showed the highest level of genetic differentiation $\left(\mathrm{F}_{\mathrm{ST}}\right)$ of all samples. It is the most isolated population, located in the outskirts of the city and separated from other neighbourhoods by undeveloped areas and adjacent to several industrial complexes (Fig. 1). The sample was obtained in a tire shop on the route connecting Córdoba with Buenos Aires, where traffic is particularly intense. Mosquitoes from this population could have originated from a mixture of individuals of different origins and this fact, together with geographic distance and discontinuity of suitable habitat, might explain the high differentiation observed.

The genetic structure of Ae. aegypti populations in Córdoba would be determined by a combination of forces: large genetic drift events every winter that differentiate populations at random and low to moderate levels of gene flow, mediated mainly by passive transport along main roads. Some level of short-distance, active dispersal would also occur, but a more detailed sampling design would be necessary to confirm this assumption. Rotela et al. (2007) studied the spreading dynamics of a recent dengue outbreak in the city of Tartagal, in Northern Argentina. They reported that the outbreak originated in a town near the city and spread along the international Route 34, which has intense national and international traffic. Within Tartagal, the epidemic spread rapidly, with the simultaneous appearance of several cases throughout the city, the authors point out the importance of the movement of people in the introduction of the virus in many houses infested with the vector. After the initial introductions, the epidemic showed a clear spatio-temporal clustering, most likely determined by Ae. aegypti flight capacity and its expected lifetime. The genetic structure of Ae. aegypti in Córdoba would favour dengue transmission dynamics similar to those found in Tartagal.

Most of the samples analysed in the present study were obtained from tire shops frequented by trucks from national and international commercial transport. In these places, tires (used, recapped or discarded) are usually stored outdoors, where they easily accumulate rainwater during the wet summer season. Several studies have addressed the idea that water-containing tires are good breeding sites for Aedes species and that desiccated eggs can be attached to them and transported large distances (Reiter \& Sprenger 1987, Reiter 1998, Nathan \& Knudsen 1991). Neighbourhoods situated at the periphery of the city could have acted as initial foci of reinfestation, from which active dispersion of females would have originated different populations within their flight ranges.

\section{REFERENCES}

Apostol BL, Black IV WC, Reiter P, Miller BR 1996. Population genetics with RAPD-PCR markers: the breeding structure of Aedes aegypti in Puerto Rico. Heredity 76: 325-334.

Avilés G, Cecchini R, Harrington ME, Cichero J, Asís R, Ríos C 1997. Aedes aegypti in Córdoba province, Argentina. J Am Mosq Control Asoc 13: 255-258.

Ayres CFJ, Melo-Santos MAV, Sole-Cava AM, Furtado AF 2003. Genetic differentiation of Aedes aegypti (Diptera: Culicidae), the major dengue vector in Brazil. J Med Entomol 40: 430-435.

Berajano JER 1968. Historia de la fiebre amarilla urbana y selvática en la República Argentina. Rev San Mil Argent 67: 211-256.

Bosio CF, Harrington LC, Jones JW, Sithiprasasna R, Norris DE, Scott TW 2005. Genetic structure of Aedes aegypti populations in Thailand using mitochondrial DNA. Am J Trop Med Hyg 72: 434-442.

Carbajo AE, Curto SI, Schweigmann NJ 2006. Spatial distribution pattern of oviposition in the mosquito Aedes aegypti in relation to urbanization in Buenos Aires: southern fringe bionomics of an introduced vector. Med Vet Entomol 20: 209-218.

da Costa-Ribeiro MC, Lourenço de Oliveira R, Failloux A-B 2006. Higher genetic variation estimated by microsatellites compared to isozyme markers in Aedes aegypti from Rio de Janeiro. Mem Inst Oswaldo Cruz 101: 917-921.

de Sousa GB, Avilés G, Gardenal CN 2000. Allozymic polymorphism in Aedes aegypti from Argentina. J Am Mosq Control Assoc 16: 206-209.

de Sousa GB, Blanco A, Gardenal CN 2001. Genetic relationships among Aedes aegypti (Diptera: Culicidae) populations from Argentina using random amplified polymorphic DNA polymerase chain reaction markers. J Med Entomol 38: 371-375.

Domínguez MC, Ludueña Almeida FF, Almirón WR 2000. Dinámica poblacional de Aedes aegypti (Diptera: Culicidae) en Córdoba capital. Rev Soc Entomol Argent 59: 41-50.

Gibbons RV, Vaughn DW 2002. Dengue: an escalating problem. BMJ 324: $1563-1566$.

Gorrochotegui-Escalante N, Munoz ML, Fernández-Salas I, Beaty BJ, Black IV WC 2000. Genetic isolation by distance among Aedes aegypti populations along the northeastern coast of Mexico. Am J Trop Med Hyg 62: 200-209.

Gubler DJ 1998. Dengue and dengue hemorrhagic fever. Clin Microbiol Rev 11: 480-496. 
Harrington LC, Scott TW, Lerdthusnee K, Coleman RC, Costero A, Clark GG, Jones JJ, Kitthawee S, Kittayapong P, Sithiprasasna R, Edman JD 2005. Dispersal of the dengue vector Aedes aegypti within and between rural communities. Am J Trop Med Hyg 72: $209-220$

Honorio NA, da Costa Silva W, Leite, PJ, Monteiro Gonçalves J, Lounibos LP, Lourenço-de-Oliveira R 2003. Dispersal of Aedes aegypti and Aedes albopictus (Diptera: Culicidae) in an urban endemic dengue area in the state of Rio de Janeiro, Brazil. Mem Inst Oswaldo Cruz 98: 191-198.

Huber K, Le Loan LE, Chanta N, Failloux A-B 2004. Human transportation influences Aedes aegypti gene flow in Southeast Asia. Acta Trop 90: 23-29.

Huber K, Le Loan LE, Hoang TH, Ravel S, Rodhain F, Failloux AB 2002. Genetic differentiation of the dengue vector, Aedes aegypti (Ho Chi Minh City, Vietman) using microsatellite markers. Mol Ecol 11: 1629-1635.

Hutchison DW, Templeton AR 1999. Correlation of pairwise genetic and geographic distance measures: inferring the relative influences of gene flow and drift on the distribution of genetic variability. Evolution 53: 1898-1914.

Jensen JL, Bohonak AJ, Kelley ST 2005. Isolation by distance, web service. BMC Genet 6: 13.

Levitan DR, Grosberg RK 1993. The analysis of paternity and maternity in the marine hydrozoan Hydractinia symbiolongicarpus using randomly amplified polymorphic DNA (RAPD) markers. Mol Ecol 2: 315-326.

Lynch, M, Milligan BG 1994. Analysis of population genetic structure with RAPD markers. Mol Ecol 3: 91-99.

Mousson L, Vazeille M, Chawprom S, Prajakwong S, Rodhain F, Failloux AB 2002. Genetic structure of Aedes aegypti populations in Chiang Mai (Thailand) and relation with dengue transmission. Trop Med Int Health 7: 865-872.

Nathan MB, Knudsen AB 1991. Aedes aegypti infestation characteristics in several Caribbean countries and implications for integrated community-based control. J Am Mosq Control Assoc 7: 400-404.

Nei M 1978. Estimation of average heterozygosity and genetic distance from a small number of individuals. Genetics 89: 583-590.

Ocampo CB, Wesson DM 2004. Population dynamics of Aedes aegypti from a dengue hyperendemic urban setting in Colombia. Am J Trop Med Hyg 71: 506-513.

Paduan KS, Araújo-Júnior JP, Ribolla PEM 2006. Genetic variability in geographical populations of Aedes aegypti (Diptera, Culicidae) in Brazil elucidated by molecular markers. Genet Mol Biol 29: 391-395.

Paupy C, Chantra N, Huber K, Lecoz N, Reynes JM, Rodhain F, Failloux AB 2004a. Influence of breeding sites features on genetic differentiation of Aedes aegypti populations analyzed on a local scale in Phnom Penh of Cambodia. Am J Trop Med Hyg 71: 73-81.
Paupy C, Chanta N, Reynes JM, Failloux AB 2005. Factors influencing the population structure of Aedes aegypti from the main cities in Cambodia. Heredity 95: 144-147.

Paupy C, Orsoni A, Mousson L, Huber K 2004b. Comparisons of amplified fragment length polymorphism (AFLP), microsatellite and isoenzyme markers: population genetics of Aedes aegypti (Diptera: Culicidae) from Phnom Penh (Cambodia). J Med Entomol 41: 664-671.

Pinheiro FP, Corber SJ 1997. Global situation of dengue and dengue haemorrhagic fever, and its emergence in the Americas. WHO Stat Q 50: 161-169.

Reiter P 1998. Aedes albopictus and the world trade in used tires, 1988-1995: the shape of things to come? J Am Mosq Control Assoc 14: 83-94.

Reiter P, Sprenger D 1987. The used tire trade: a mechanism for the worldwide dispersal of container breeding mosquitoes. $J \mathrm{Am}$ Mosq Control Assoc 3: 494-501.

Reynolds J, Weir BS, Cockerham CC 1983. Estimation of the coancestry coefficient: basis for a short-term genetic distance. Genetics 105: 767-779.

Rondán Dueñas JC 2005. Estructura genética de poblaciones sudamericanas de Aedes aegypti (Diptera: Culicidae). Inferencia de patrones de colonización, PhD Thesis, Universidad Nacional de Córdoba, Córdoba, 150 pp.

Rotela C, Fouque F, Lamfri M, Sabatier P, Introini V, Zaidenberg M, Scavuzzo C 2007. Space-time análisis of the dengue outbreak spreading dynamics in the 2004 Tartagal outbreak, Northern Argentina. Acta Trop 103: 1-13.

Rousset F 1997. Genetic differentiation and estimation of gene flow from F-statistics under isolation by distance. Genetics 145: 1219-1228.

Sambrook J, Fritsch EF, Maniatis T 1989. Molecular cloning: a laboratory manual, 2nd ed., Cold Spring Harbor Laboratory, New York, 253 pp.

Tran Khanh T, Vazeille-Falcoz M, Mousson L, Tran Huu H, Rodhain F, Nguyen Thi H, Failloux AB 1999. Aedes aegypti in Ho Chi Minh city (Vietnam): susceptibility to dengue 2 virus and genetic differentiation. Trans R Soc Trop Med Hyg 93: 581-586.

Vekemans X, Beauwens T, Lemaire M, Roldan-Ruiz I 2002. Data from amplified fragment length polymorphism (AFLP) markers show indication of size homoplasy and of a relationship between degree of homoplasy and fragment size. Mol Ecol 11: 139-151.

Vezzani D, Rubio A, Velázquez SM, Schweigmann N, Wiegard T 2005. Detailed assessment of microhabitat suitability for Aedes aegypti (Diptera: Culicidae) in Buenos Aires, Argentina. Acta Trop 95: 123-131.

Wright S 1978. Evolution and the genetics of populations. Vol. 4: Variability within and among natural populations, University of Chicago Press, Chicago, 580 pp.

Zhivotovsky LA 1999. Estimating population structure in diploids with multilocus dominant DNA markers. Mol Ecol 8: 907-913. 